\title{
Surface Forces in Unconventional Oil Processing
}

\author{
Nina O. Ivanova ${ }^{\mathrm{a}}$, Zhenghe $\mathrm{Xu}^{\mathrm{a}, \mathrm{b} *}{ }^{\text {, Qingxia Liu }}{ }^{\mathrm{a}}$, Jacob H. Masliyah ${ }^{\mathrm{a}}$
}

\begin{abstract}
As the world population and energy demand grow every year, unconventional oil plays an increasingly more important role in satisfying our energy needs. At 3.2 trillion barrels of currently recoverable unconventional oil, and with in-place reserves putting Canadian oil sands alone at 1.7 trillion barrels, it is becoming increasingly important to find both economical and environmentally sound technologies to bring this resource to market. Characterized by its high density and high viscosity, many extraction methods that currently exist are expensive and/or provide low oil recovery. To develop new technologies, understanding fundamental surface science behind the two main steps of oil extraction oil liberation from host rocks and separation of oil from water/oil and oil/water emulsions - is of critical importance. All the interactions between host rocks, oil, clays, asphaltenes, bubbles, and connate water are governed by surface forces. In this review, surface forces will be presented as a practical tool in understanding fundamental processes governing unconventional oil extraction. Following a thorough literature overview, the challenges, knowledge gaps and future research opportunities are discussed.
\end{abstract}

Keywords: Surface Forces, Unconventional Oil, Oil Liberation, Aeration-Flotation, Emulsion, Adhesion Forces.

\section{Introduction}

This review examines the role surface forces play in unconventional oil processing and how understanding colloidal interactions could lead to improved understanding of various interactions that drive fundamental processes during oil processing. A thorough recent review regarding interfacial sciences in petroleum production by He et al. ${ }^{1}$ touched on surface forces, but only briefly, and a more detailed review on the topic is needed. The last review on surface forces in unconventional oil processing back in $2009^{2}$ focused only on the subject of atomic force microscopy. The current review encompasses several surface force measurement techniques, with a focus on the latest findings.

Unconventional oil simply refers to oil that cannot be extracted and processed using conventional methods. According to the International Energy Agency, ${ }^{3}$ unconventional oil includes kerogen shale, oil sands/tar sands, tight oil and oil derived from coal-to-, gas-to- and biomass-to-liquids. Alternatively, unconventional oil has been defined by its high viscosity, high density (below $20^{\circ}$ API or above $934 \mathrm{~kg} / \mathrm{m}^{3}$; "heavy oil") or the geological settling of the reservoir. ${ }^{3}$ In this review, we will use the latter definition (high viscosity and high density), with bitumen as an example: density of $1003 \mathrm{~kg} / \mathrm{m}^{3}$ and viscosity of $250 \mathrm{~Pa} \cdot \mathrm{s}$ at $20^{\circ} \mathrm{C}$. Predominately found in North America, Eastern Europe and Latin 
America, just over half of world oil reserves are unconventional oil at 3.2 trillion barrels ${ }^{5}$ recoverable with current technologies. In-place reserves of unconventional oil are much larger, with Canadian oil sands alone representing 1.7 trillion barrels ${ }^{1}$ of bitumen. Improving extraction technologies is critical to fully harness this energy resource, with fundamental studies of surface forces governing unconventional oil extraction processes paving the way.

Currently, extraction technologies for unconventional oil fall into two categories: miningextraction and in-situ production. For shallow deposits (less than about $70 \mathrm{~m}$ ), open-pit mining can be used, while for deeper deposits in-situ techniques are employed. ${ }^{6}$ The mining-extraction method uses the Clark hot-water extraction process which typically involves crushing of mined ores and mixing of the crushed ores with warm water and process aids (e.g. $\mathrm{NaOH}$ ) to form a slurry that is transported via a hydrotransport slurry pipeline. Under the favorable physicochemical condition, the turbulence in the pipeline causes heavy oil (bitumen) to detach from solid particles and become aerated with entrained air. ${ }^{4}$ This slurry then enters a gravity separation vessel, where the aerated bitumen is collected as a bitumen froth consisting roughly of $60 \mathrm{wt} \%$ bitumen, $30 \mathrm{wt} \%$ water and $10 \mathrm{wt} \%$ solids. ${ }^{7}$ Finally, bitumen is demulsified, separating bitumen from water and solids for subsequent upgrading to a synthetic crude oil (SCO). With in-situ production, many techniques ${ }^{8}$ are used that can be broadly divided into thermal and non-thermal methods. Thermal methods use hot water and steam (such as cyclic steam stimulation (CSS) and steam-assisted gravity drainage (SAGD)) to lower the viscosity of heavy oil and hence facilitate heavy oil migration to production well. Non-thermal methods rely on injections of miscible or immiscible fluids along with chemicals, aimed at lowering the interfacial tension and improving the mobility ratio. ${ }^{8}$ Carbon dioxide and inert gases are popular for both miscible and immiscible injections, while chemical flooding with the addition of polymers, surfactants, alkaline and combinations thereof is less common due mainly to economic concerns.

Regardless of the production method, there are two essential steps involved in unconventional oil extraction: oil liberation from host rocks or reservoir solids (Figure 1:a-b) and the separation of water (either connate or added as extraction aid) and oil (Figure 1:c-d). Oil liberation can be subdivided into two sub-processes: bitumen recession and bitumen/solid detachment (Figure 1-a). The most important interaction is between heavy oil and host rock/sand in processing fluids. There are two methods of oilwater separation: i) flotation through oil-air bubble attachment and ii) creaming/sedimentation of dispersed oil/water droplets through flocculation/coalescence. Numerous interactions are involved in oil-water separation, as shown in Figure 1-b and 1-c, respectively. In flotation, attractions between air bubbles and oil droplets are essential while interactions between air bubbles and solids and/or between solids and oil would interfere with the separation. The oil-oil interaction also plays an important role in flotation due to extreme difficulties in attachment of small oil droplets to flotation size bubbles. In oilwater separation by creaming or sedimentation, demulsification of water-in-oil (W/O) and oil-in-water $(\mathrm{O} / \mathrm{W}$ ) emulsions (Figure 1-c) is essential, where oil-oil, water-water and asphaltene-solvent interactions are important in determining the success of the demulsification process. Oil-in-water (O/W) emulsions are most commonly observed during water-flooding and hydrotransport, while water-in-oil (W/O) emulsions are found further along the extraction route, including bitumen froth treatment, crude oil transportation and oil desalting. ${ }^{9}$ While thermodynamically unstable, these emulsions have remarkable 
kinetic stability often attributed to surface active species, such as asphaltenes (Figure 1-c, orange inset) and small mineral solids (fines, Figure 1-b)) that migrate to the water-oil interface. Asphaltenes are a solubility class, defined as soluble in toluene but insoluble in $n$-alkanes. Clays can make up 15-30 wt $\%$ of solids in the mined oil sands, predominantly kaolinite and illite. ${ }^{4}$ More details regarding asphaltenes and clays in unconventional petroleum can be found elsewhere. ${ }^{10}$ Destabilization of such emulsions is largely determined by the properties and stability of interfacial thin films between approaching droplets. Many factors can influence all of these interactions, including the presence of electrolytes, endogenous surface-active species and fines (e.g. clays), along with process parameters such as temperature, $\mathrm{pH}$, weathering and the addition of potential processing aids, to name a few. All these interactions that determine the success of unconventional oil production are governed by surface forces. Better understanding of surface forces will lead to more economical and environmentally-sound unconventional oil extraction techniques.

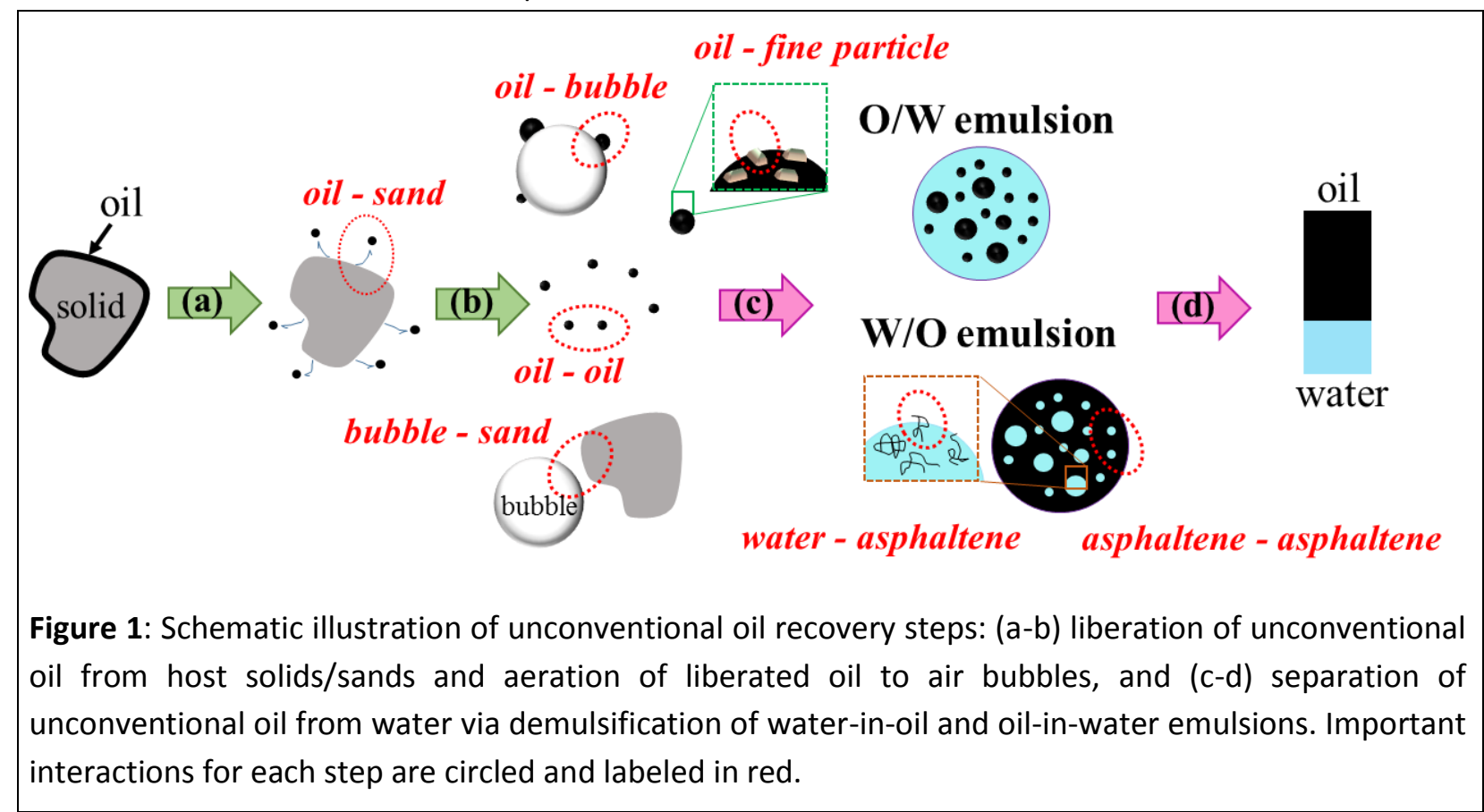

\section{Experimental Techniques}

Background information regarding Atomic Force Microscope (AFM), Surface Force Apparatus (SFA), Thin Liquid Film (TLF) technique and Surface Forces in general can be found in Supporting Information. The Integrated Thin Film Drainage Apparatus (ITFDA) is a new, custom designed instrument and for this reason will be discussed in this review. Table 1 below summarizes the major findings for interactions shown in Figure 1, sorted by experimental technique.

The ITFDA, developed by Wang et al. ${ }^{11}$ and shown in Figure $2-a^{11}$, has some added benefits to the simpler TLF technique. The ITFDA allows the direct and simultaneous measurement of numerous parameters, including: interaction forces and thin film drainage dynamics over a wide range of hydrodynamic conditions. Specifically, it covers interactions in the intermediate Reynolds number regime (between 0.01 and 100) that cannot be studied by any of the previously listed instruments while 
often encountered in unconventional oil production. Briefly, a droplet (or bubble) is generated inside a glass capillary via an air-tight syringe. A motorized actuator coupled with a speaker diaphragm allows for precisely controlled vertical approach of the droplet at a wide range of speeds $(0.01-50 \mathrm{~mm} / \mathrm{s}) .{ }^{11}$ The lower surface (a glass sphere in Figure 2-a) is attached to the free end of a piezoelectric bimorph ${ }^{12}$ (shown in Figure 2-b) that allows the direct measurement of interaction forces with a sensitivity of up to $0.1 \mu \mathrm{N}$. The ITFDA can be used to measure interaction forces between air bubbles and solids, liquid droplets or another air bubble, between two liquid droplets, and between droplets and solids in a fluid, as encountered in unconventional oil recovery process outlined in Figure 1. The instrument has recently been modified in our group to replace the glass sphere in Figure 2-a to a transparent silica window that allows for better overlap control and film thickness monitoring via interference fringes.

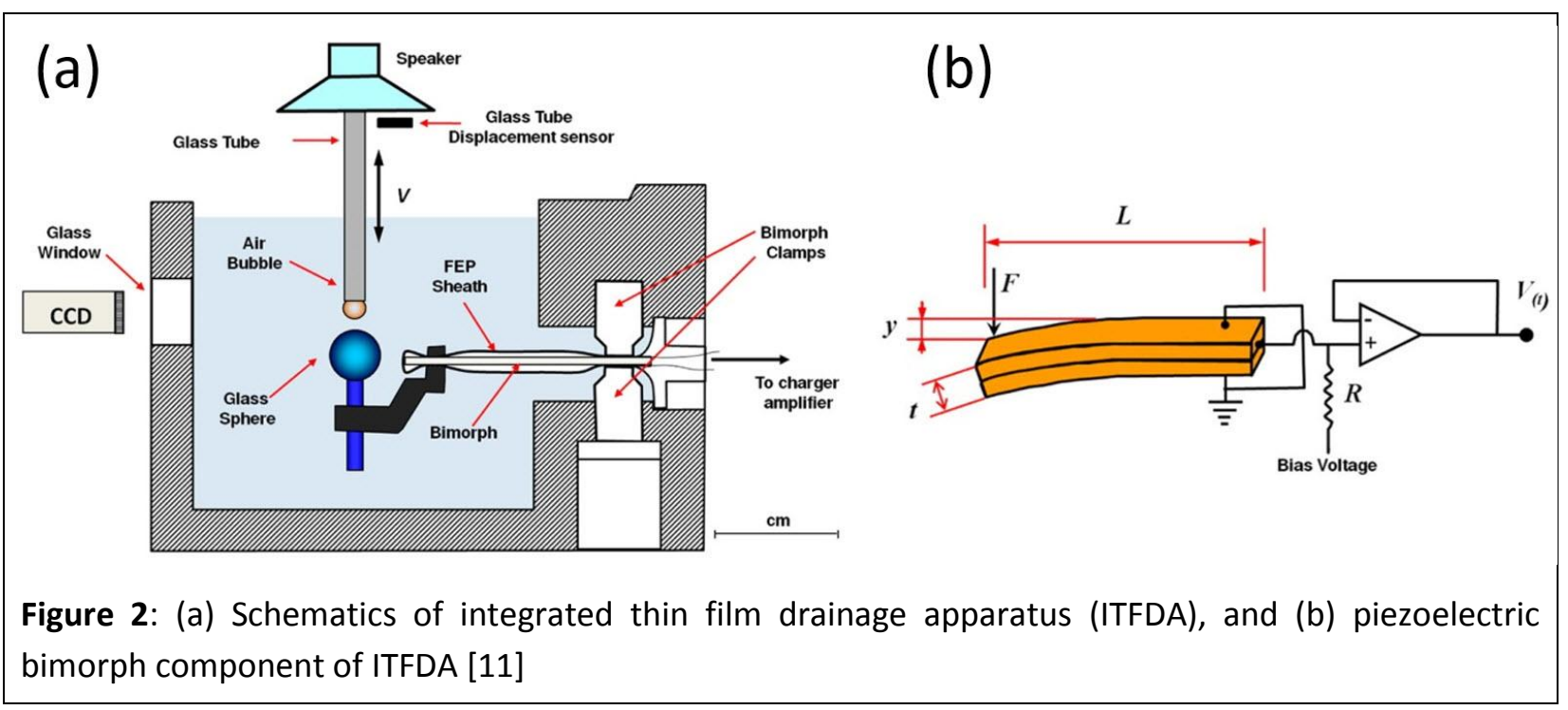

\section{Surface Forces in Unconventional Oil Liberation (Oil/Water/Sand)}

Heavy oil is typically found impregnated in host rocks or solid minerals. The rock/mineral composition varies by location, and typically consists of carbonate rocks (e.g.: calcite, dolomite, etc.), sands (e.g.: silica, kaolinite or aluminum silicate, etc.), clays and heavy minerals. ${ }^{1}$ The size of solids varies widely, from a micron-sized clay platelet to a rock on the scale of meters. Fine mineral solids or "fines" will be discussed separately in section 4.4. The interaction between unconventional oil and solid surface is key in determining the success of oil liberation from host rocks. Though many natural host rocks are porous and heterogeneous, it is easier to elucidate oil (bitumen)-solid surface forces in aqueous medium when using a "model" host surface, most often a silica or mica surface. DLVO and extended DLVO theory (see Supporting Information) is used to interpret the results. In a typical experiment, bitumen is coated onto a colloidal probe or a flat surface (e.g.: silicon wafer) via dip-coating or Langmuir-Blodgett films to represent the heavy oil surface in the colloidal force measurement by AFM techniques. In general, a soft surface (such as bitumen) would deform during a colloidal force measurement. However, if the bitumen layer coated on solids is sufficiently thin (less than $100 \mathrm{~nm}$ ), no noticeable deformations of such bitumen films have been observed ${ }^{34}$ and thus deformation effects can be safely neglected. 
Table 1: Summary of major research findings using different techniques ${ }^{a}$ for each interaction type (system).

\begin{tabular}{|c|c|c|c|}
\hline System & Technique & Major Findings & References \\
\hline \multirow[t]{2}{*}{$\begin{array}{l}\text { Oil/Water/Sand } \\
\text { (oil liberation) }\end{array}$} & AFM & $\begin{array}{l}\text { Increasing temperature or } \mathrm{pH} \\
\text { decreases adhesion and increases } \\
\text { repulsion; } \\
\text { - Divalent cations decrease repulsion } \\
\text { and increase adhesion; }\end{array}$ & $1,7,13-24$ \\
\hline & Zeta Potential & $\begin{array}{l}\text { Weathered ores benefit from UV } \\
\text { exposure and bicarbonate ions; } \\
\text { - } \quad \text { lonic liquids lower adhesion. }\end{array}$ & $14,18,19,21$ \\
\hline \multirow{2}{*}{ Oil/Water/Bubble } & AFM & $\begin{array}{l}\text { - Adding cationic surfactant or } \\
\text { decreasing } \mathrm{pH} \text { increases attraction. }\end{array}$ & 25,26 \\
\hline & ITFDA & $\begin{array}{l}\text { - Increased hydrophobicity and slower } \\
\text { approach velocity improves oil/bubble } \\
\text { attachment. }\end{array}$ & 11,27 \\
\hline \multirow[t]{2}{*}{ Bubble/Water/Sand } & AFM & $\begin{array}{l}\text { - Hydrophobic force is the driving } \\
\text { attractive force; } \\
\text { Van der Waals and electrostatic } \\
\text { interaction is repulsive. }\end{array}$ & $25,27-32$ \\
\hline & ITFDA & $\begin{array}{l}\text { - Increased hydrophobicity and slower } \\
\text { approach velocity improves } \\
\text { bubble/sand attachment. }\end{array}$ & 27,33 \\
\hline \multirow[b]{2}{*}{ Oil/Water/Oil } & AFM & $\begin{array}{l}\text { - Decreasing } \mathrm{pH} \text { increases attraction } \\
\text { and adhesion; }\end{array}$ & $14,34-36$ \\
\hline & Zeta Potential & $\begin{array}{l}\text { Addition of calcium ions and } \\
\text { montmorillonite clay increases } \\
\text { repulsion and causes slime coating. }\end{array}$ & 14 \\
\hline \multirow[t]{2}{*}{$\begin{array}{l}\text { Oil/Water/Fines } \\
\text { (slime coating) }\end{array}$} & AFM & $\begin{array}{l}\text { Increasing temperature causes } \\
\text { increased repulsion and decreased } \\
\text { adhesion force; } \\
\text { Addition of calcium ions and } \\
\text { montmorillonite clay reduces } \\
\text { repulsion and increases adhesion, } \\
\text { causing slime coating; }\end{array}$ & $\begin{array}{c}1,7,13,14,17,19 \\
22-24,35-44\end{array}$ \\
\hline & Zeta Potential & $\begin{array}{l}\text { - Interaction is repulsive for good ore } \\
\text { - } \quad \text { fines and attractive for poor ore fines; } \\
\text { reduces attraction and adhesion in } \\
\text { weathered/poor ore fines. }\end{array}$ & $14,19,35,40,45,46$ \\
\hline \multirow[t]{2}{*}{$\begin{array}{l}\text { Oil/Water/Oil } \\
\text { (emulsions, } \\
\text { asphaltenes) }\end{array}$} & AFM & $\begin{array}{l}\text { Decreasing temperature or } \mathrm{pH} \\
\text { decreases repulsion and increases } \\
\text { adhesion; } \\
\text { - } \\
\text { Repulsion is electrostatic (long-range) } \\
\text { and steric (short-range) in origin; } \\
\text { Electrolyte addition decreases } \\
\text { repulsion. }\end{array}$ & $1,32,47-49$ \\
\hline & SFA & $\begin{array}{l}\text { - } \quad \text { Model asphaltene compound C5Pe } \\
\text { showed similar interactions to AFM }\end{array}$ & 50 \\
\hline
\end{tabular}




\begin{tabular}{|c|c|c|c|}
\hline & & findings above. & \\
\hline \multirow{4}{*}{$\begin{array}{l}\text { Water/Oil/Water } \\
\text { (emulsions, } \\
\text { asphaltenes) }\end{array}$} & AFM & $\begin{array}{l}\text { Good asphaltene solvent (toluene) } \\
\text { results in swelling and increased } \\
\text { repulsion; } \\
\text { - Poor asphaltene solvent ( } n \text {-heptane) } \\
\text { causes weak attractive Van der Waals; }\end{array}$ & $1,51,52$ \\
\hline & SFA & $\begin{array}{l}\text { Asphaltene adsorbs on interface over } \\
\text { time, repulsion/attraction increases } \\
\text { over time; } \\
\text { C5Pe did not swell in toluene, other } \\
\text { behaviour similar to asphaltenes. }\end{array}$ & $53-56$ \\
\hline & ITFDA & $\begin{array}{l}\text { Coalescence time increases over time } \\
\text { due to increased interfacial elasticity; }\end{array}$ & 57 \\
\hline & TLF & $\begin{array}{l}\text { Thicker films form over time with } \\
\text { positive disjoining pressure at high } \\
\text { asphaltene concentration. }\end{array}$ & $58-64$ \\
\hline
\end{tabular}

${ }^{a}$ Major findings separated by a dotted line pertain to both techniques; for example, as with AFM and Zeta Potential findings for Oil/Water/Sand interaction.

Using AFM Long et al. ${ }^{13}$ determined the effect of temperature on long-range interaction forces between heavy oil (bitumen) and silica in industrial process water. Increasing the temperature from ambient to $39.4^{\circ} \mathrm{C}$ was found to make the interaction progressively more repulsive, while decreasing the adhesion force to zero at $32^{\circ} \mathrm{C}$. The results confirmed the beneficial role of higher temperatures for bitumen liberation. In fact, it identified the minimal processing temperature of $32^{\circ} \mathrm{C}$ that guided industrial operations. Similar experiments were carried out by Liu et al., ${ }^{14}$ exploring the effects of electrolyte $(\mathrm{KCl})$, divalent cation $\left(\mathrm{Ca}^{2+}\right)$ and $\mathrm{pH}$ on bitumen-silica interaction. Increasing $\mathrm{pH}$ from 3.5 to 10.5 led to an increasingly more repulsive interaction between bitumen and silica and a reduction in adhesion force down to zero at $\mathrm{pH}=10.5$. Repulsive force overtakes the adhesion force at $\mathrm{pH}^{\sim-8}$, corresponding closely with experimental results of easy bitumen liberation. Increasing $\mathrm{KCl}$ addition led to electrical double layer compression and the reduction in repulsive interaction, but even at $100 \mathrm{mM}$ the interaction remained repulsive as anticipated. ${ }^{14}$ Such observation corresponded well with the observed insignificant effect of monovalent electrolytes on bitumen liberation. Calcium is a common electrolyte naturally present in waters associated with oil sands deposits. It may also be introduced artificially into the bitumen extraction operation via recycle of process water from gypsum-treated consolidated tailings. ${ }^{65}$ Unlike $\mathrm{KCl}$, divalent calcium ions showed a profound effect on decreasing repulsive interaction between bitumen and silica, especially at higher $\mathrm{pH}$. At $\mathrm{pH}=8.2$ for example, only $0.1 \mathrm{mM} \mathrm{Ca}^{2+}$ led to heterocoagulation of silica on bitumen, impeding bitumen liberation from reservoir rock surfaces.

Surfactants play an important role in bitumen recovery from unconventional oil resources such as oil sands. The sulfate/sulfonate and carboxylate anionic surfactants known to be present in heavy oil that are extracted to the oil-water interface and into process water. ${ }^{4}$ The bitumen-water interface for example has been deduced to contain surface polar molecules with cationic $\left(\mathrm{RNH}_{3}{ }^{+}\right)$and anionic $\left(\mathrm{RCOO}^{-}\right.$, $\mathrm{ROSO}_{3}{ }^{-}$) moities. ${ }^{66}$ Therefore, it is helpful to study the impact of cationic and anionic surfactants on the various steps of the oil recovery process. Using AFM and zeta potential distribution measurements, Zhao 
et al. ${ }^{15}$ measured colloidal forces between bitumen and silica in the presence of two divalent cations $\left(\mathrm{Ca}^{2+}, \mathrm{Mg}^{2+}\right)$ and anionic surfactant SDS (sodium dodecyl sulfate) at neutral to alkaline $\mathrm{pH}$. As with previous studies, the presence of divalent cations had a negative effect on bitumen liberation due to decreased long-range repulsion and increased adhesion. This was consistent with zeta potential distribution measurement that indicated silica-bitumen heterocoagulation in the presence of $\mathrm{Ca}^{2+}$ and $\mathrm{Mg}^{2+}$. Addition of anionic SDS binds divalent cations, thus mitigating their negative effects and improving bitumen liberation. However, Zhang et al. ${ }^{16}$ found an increased adhesion and attractive long-range force with the addition of anionic SDS as compared to the interaction for calcium ions alone at similar $\mathrm{pH}$ values. Unlike Zhao et al., ${ }^{15}$ the concentration of calcium ions used in the study by Zhang et al. was much higher (with the same $\mathrm{KCl}$ background). More studies are needed to fully understand the effect surfactants have on bitumen-silica interactions in the presence of divalent cations.

Weathering or aging is a natural phenomenon that can affect characteristics of heavy oil reservoirs and oil sands deposits. ${ }^{17}$ Ore weathering can result in changes in both chemical and physical properties such as oxidation of the heavy oil components and/or loss of formation water and volatile light end components of oil. ${ }^{17}$ Ren et al. ${ }^{19}$ studied, via AFM, the impact of weathering on interaction and adhesion forces between various silica spheres and heavy oil (bitumen)-covered silicon wafer in water at $\mathrm{pH}$ 8-8.6 with $1 \mathrm{mM} \mathrm{KCl}$. The following silica probes were used: (1) model, (2) mixed with good processing ore, (3) mixed with weathered ore (artificially aged for $60^{\circ} \mathrm{C}$ for 1 week) and (4) probe 3 exposed to UV light for 12 hours. Bitumen type (weathered or not) had a negligible effect on measured long-range interaction forces between bitumen and model silica, supporting the use of commercially extracted bitumen for all measurements. ${ }^{19}$ As expected, probe 1 and bitumen showed a strong repulsive force and no adhesion force. Probe 2 and bitumen showed a weaker repulsion and stronger adhesion, while the weathered probe 3 showed even weaker repulsion and very strong adhesion to bitumen. Thus weathered ore (or reservoir) makes bitumen liberation from sand grains difficult, leading to reduced bitumen recovery. Probe 4 had the same response as probe 1, which shows UV exposure to be an effective tool to mitigate reservoir weathering. Ren et al. ${ }^{67}$ reported that adsorption of organic materials onto the surface of weathered ores was responsible for their hydrophobicity. Zhao et al. ${ }^{18}$ identified a beneficial effect of bicarbonate ion on bitumen recovery from poor processing oil sand ores (low-grade bitumen, with a high amount of divalent cations, fines and hydrophobic solids). AFM measurements of the adhesion force between bitumen and silica showed a much lower adhesion force when bicarbonate ions were present in process water. Naturally, lower adhesion between bitumen and sand grain is desirable for bitumen liberation. They also found that bicarbonate ions acting as a buffer can reduce the demand for $\mathrm{NaOH}$ addition and slime coating. ${ }^{18}$

Finally, it is worth mentioning that oil liberation from reservoir could also be done in lonic liquids (IL) instead of using water. IL's are composed of anions associated with organic cations that melt at or below $100^{\circ} \mathrm{C}^{20}$ One of their advantages is the absence of volatility, thus making them much less toxic than low boiling point solvents. Using AFM, Hogshead et al. ${ }^{20}$ measured interactions between silica and bitumen from Alberta and Utah oil sands. They found an order of magnitude lower adhesion in IL (1butyl-2,3-dimethyl-imidazolium tetrafluoroborate) than in an aqueous solution. They hypothesized the 
layered charge structures of ionic liquids on surfaces being the cause of lower adhesion between bitumen and silica.

\section{Oil-Bubble Attachment in Recovery}

\section{$\underline{4.1 \text { Oil/Water/Bubble }}$}

One of effective methods to separate liberated heavy oil from flooding fluid would be by flotation under a buoyancy force after attaching gas (mostly air) bubbles to the oil droplets. This is practised in bitumen recovery from Canadian oil sands by mining-extraction method where the heavy oil (bitumen) and processing fluid (water) have similar densities at common extraction temperatures. In this case as in most mineral flotation systems, bubble-oil (bitumen) attachment is critical in bitumen froth flotation. Although bitumen and air bubble both could be considered naturally hydrophobic and their attachment in water should be spontaneous, the presence of natural surfactants in bitumen and hence process water could render both bitumen-water and air-water interface much less hydrophobic due to the adsorption of natural surfactants, mostly of anionic nature. The adsorption of anionic natural surfactants at both oil-water and air-water interface makes them negatively charged, with the magnitude of the surface charge and surface hydrophobicity depending highly on the $\mathrm{pH}$ of aqueous phase. ${ }^{7}$ From a surface forces perspective, van der Waals forces are repulsive for bitumen-air bubble attachment in an aqueous medium. ${ }^{69}$ The electrostatic interaction is also highly repulsive, although the magnitude of repulsion can be tuned by changing the $\mathrm{pH}$ or electrolyte concentration of processing medium. Based on the classical DLVO theory, the air bubble-bitumen attachment is highly unfavorable if not impossible. As a result, an additional attractive force needs to be created to achieve air bubblebitumen attachment in aqueous process medium. In fact, the attractive forces that originate from surface hydrophobicities are the main driving force for the observed air bubble-bitumen attachment. ${ }^{7}$

Anionic surfactants are known to be present in bitumen, which are transferred to bitumenwater interface and released into the process water during extraction, ${ }^{7}$ leading to a system shown in Figure 3-a. Using a 10-nm bitumen layer dip-coated on silica particle in AFM colloidal probe technique, ${ }^{19}$ Ren et al. ${ }^{26}$ studied air bubble-bitumen interactions in aqueous solutions containing either DTAC (cationic, dodecyl trimethyl ammonium chloride) or DSA (anionic, dodecane sulfonic acid) surfactants. A weakly attractive force is observed between the air bubble and the probe in DTAC solution, as shown in Figure 3-b. Conversely, a strong repulsion was observed between the air bubble and the probe in DSA solution (Figure $3-d$ ). The results clearly show the need to compromise the operating conditions to optimize bubble-bitumen attachment without sacrificing bitumen liberation, as practiced in industrial operations at $\mathrm{pH}$ 8.5. Another approach is to introduce cationic surfactants after bitumen liberation from sand grains in order to enhance air bubble-bitumen attachment for more effective recovery of bitumen. In fact this was confirmed by Wang et al. ${ }^{70}$

Englert et al. ${ }^{25}$ measured interaction forces between an air bubble and bitumen-coated silica colloidal probe in aqueous solutions of $\mathrm{pH} 3.5,5.7$ and 10 via AFM. They observed a repulsive region prior to a jump-in, resulting in 3-phase contact upon rupture of intervening liquid film. The maximum repulsion experienced increases with $\mathrm{pH}$. It was proposed that the presence of carboxylic acid groups 
(deprotonated at high $\mathrm{pH}$ ) in bitumen is responsible for the increase in the long-range repulsive force. The experimental data fit well with White-Dagastine-Prieve-Chan model. ${ }^{71}$ Further theoretical testing of model variables showed a significant impact of solution ionic strength, surface potentials and the radii of the bubble and bitumen-coated probe on interaction forces between bitumen and air bubbles. As an example, Figures 3-e and 3-f show the influence of surface potential and silica probe radius on bubblebitumen interaction, respectively, where a higher surface potential or smaller silica probe particle leads to an increased repulsive force and a larger jump-in distance with lower force barrier. With ITFDA, Wang et al. ${ }^{27}$ investigated thin film drainage of intervening water between an air bubble and a solid of varied hydrophobicity over a range of approach velocities from $2 \mu \mathrm{m} / \mathrm{s}$ to $2000 \mu \mathrm{m} / \mathrm{s}$. They found that faster approach velocities lead to slower thin film drainage to reach three phase contact or steady state film thickness of stable films (hydrodynamic effects). Increasing hydrophobicity of solids on the other hand reduces significantly the force barrier to resist thin film drainage before reaching three phase contact.

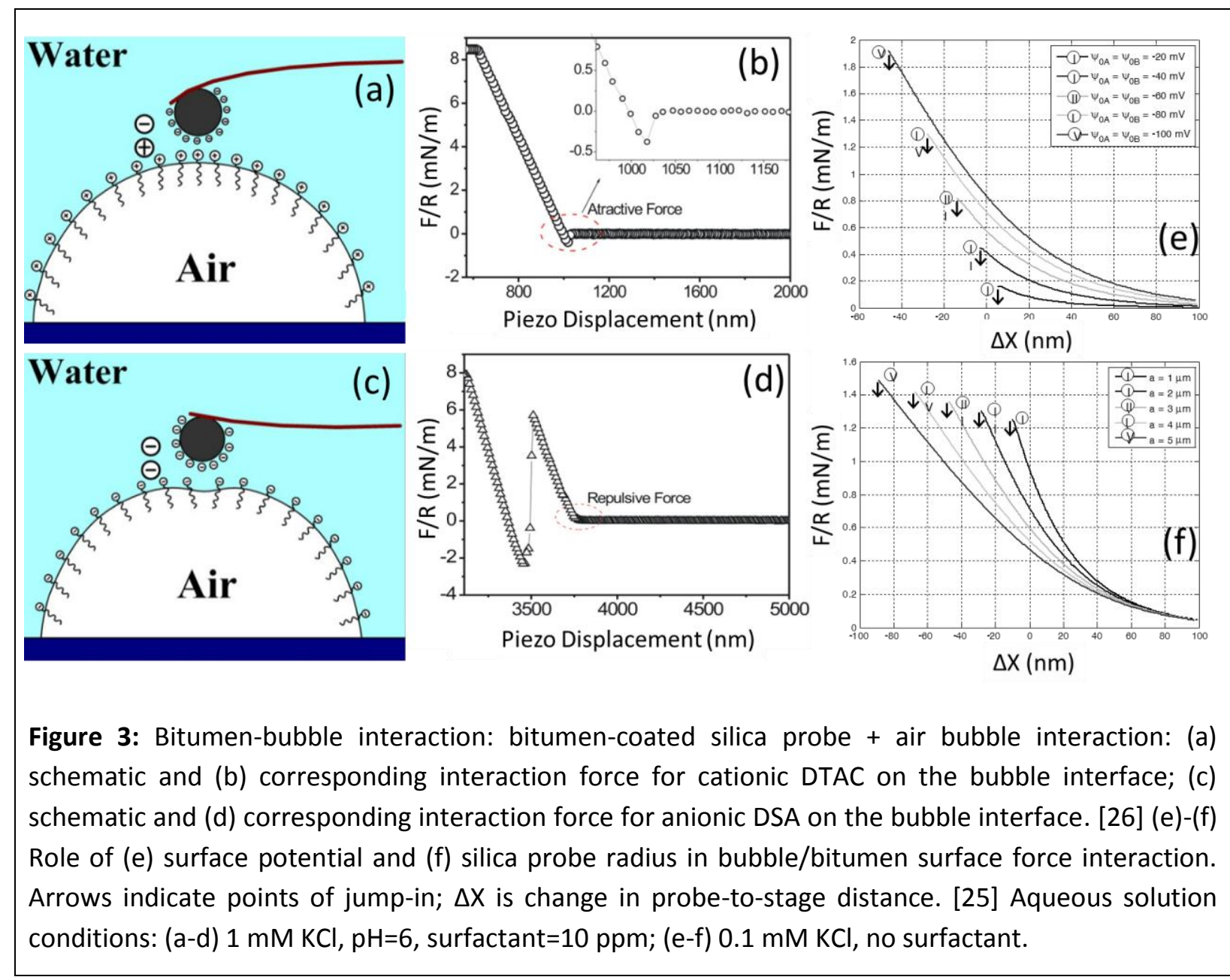

ITFDA has been used to measure the attachment time of heavy oil (bitumen) droplets with air bubble in a sea water. ${ }^{27}$ The results for a given bubble approaching velocity of $240 \mu \mathrm{m} / \mathrm{s}$ showed a significant increase in attachment time from $0.83 \mathrm{~s}$ to $6.8 \mathrm{~s}$ with increasing aging time of oil droplets in the sea water of natural $\mathrm{pH} 7.6$ to $5 \mathrm{~min}$, indicating significant role of natural surfactant adsorption at 
oil-water interface on interactions of bubble-oil droplet attachment. It is, however, interesting to note a negligible effect of $\mathrm{pH}$ on the time of oil droplets attaching to the air bubble in sea water. Further systematic study on the attachment of air bubbles to oil droplets over a wide range of physicochemical conditions with ITFDA would shed lights on molecular mechanisms of bubble-oil droplet interactions and provide more insights into enhancing oil recovery by flotation.

\subsection{Bubble/Water/Sand}

Although attachment of hydrophobized target mineral particles to air bubbles is essential for recovering valuable minerals by flotation, such attachment is highly undesirable in heavy oil recovery by flotation as the solids attached to air bubbles would be entrapped in oil product, causing problems in downstream processing of oil. Studying bubble-solid interactions is therefore of both great theoretical and practical importance. Two of the first studies on interactions between air bubble and solid surfaces in aqueous solutions were conducted by Ducker et al. ${ }^{29}$ and Butt ${ }^{72}$ using a silica sphere colloidal probe in AFM. For the bubble interacting with sand in aqueous media, van der Waals forces will be repulsive. ${ }^{30,69}$ Ducker et al. ${ }^{29}$ clearly showed the presence of a strong, long-range attractive force not accounted for by the classical DLVO theory, known as hydrophobic force with the fresh bubble being a hydrophobic surface. The hydrophobic force was found to disappear upon the addition of an anionic surfactant to the aqueous solution, most likely as a result of anionic surfactant adsorption onto the bubble surface that rendered the bubble hydrophilic. Butt et al. ${ }^{31}$ looked at the role of surfactants in bubble-particle interactions and found that both anionic and cationic surfactants (at or above critical micelle concentration) cause a repulsive force between particle and air-water interface. In a different approach, Chan et al. ${ }^{32}$ described an experiment where a bubble in a capillary was lowered towards a quartz surface. The final equilibrium film was found to be stabilized by electrical double layer repulsion, and increasing salt concentration caused double layer compression and a thinner equilibrium film. Using ITFDA, Wang et al. ${ }^{27}$ investigated the effect of solid surface hydrophobicity and approach velocity on the surface force profiles of an air bubble approaching a glass surface in water. Increasing bubble approach velocity was found to cause a linear increase in film drainage resistance (average film pressure). Since surface forces were independent of bubble approach velocity, all the changes in the measured film pressure were attributed to hydrodynamics of the system. Interestingly for a given bubble approach velocity where hydrodynamics could be considered the same, increasing surface hydrophobicity led to a lower film drainage resistance, clearly illustrating long range effect of surface hydrophobicity on the flow of intervening liquid. Such interesting response of liquid flow to hydrophobicity of solid surface is most likely linked with the change in solid-liquid boundary conditions, which deserves further systematic investigations. ${ }^{73}$ It would also be helpful to determine the length scale of separation at which hydrodynamics would be sufficient to achieve oil/sand separation. Despite the significance of bubbleparticle interactions in recovery of high quality heavy oil by flotation, there is little attention paid to probing interactions between air bubbles and oil-contaminated solids. It is well known that heavy oil (bitumen) froth produced by flotation contains about 10 wt\% solids, mainly fine clays and heavy minerals. These solids are mostly contaminated by organic matter from bitumen. Studying the reporting mechanisms of fine solids to bitumen froth through colloidal force measurement would lay a foundation 
to reducing the solids content in bitumen froth that have detrimental impact on subsequent bitumen froth cleaning.

\subsection{Oil/Water/Oil}

Oil-oil interactions are important during unconventional oil recovery as well as during oil-water separation. Ideally, oil droplets will coalesce together and eventually become phase separated for easy removal of solids and water from the heavy oil product. Oil-oil interactions related to emulsions and surface active species (e.g.: asphaltenes) will be discussed in section 5 . Here the focus will be on recovery of heavy oil by flotation. Considering that heavy oil (bitumen) droplet collision efficiency is directly related to droplet size, oil-oil interactions to promote coalescence are especially important to improve bitumen "aeration". ${ }^{7}$

Using the AFM probe technique, Liu et al. ${ }^{14,34}$ measured interaction forces between bitumen in aqueous solutions $\left(1 \mathrm{mM} \mathrm{KCl}\right.$ ) as a function of solution $\mathrm{pH}$ and $\mathrm{Ca}^{2+}$ concentration. A colloidal probe and a silicon wafer were both coated with bitumen to simulate two interacting bitumen surfaces. Below $\mathrm{pH}$ 3.5 , the interaction force between two bitumen surfaces was found to be attractive, which became progressively repulsive until $\mathrm{pH} 10.5$ as a result of increasing ionization of natural surfactant in bitumen that makes bitumen surfaces increasingly negatively charged and less hydrophobic upon their adsorption/partition at the bitumen-water interface. Increasing $\mathrm{pH}$ led to a significant decrease in the adhesion force. Since low repulsion (or attractive force) and high adhesion are desirable for oil-oil droplet coalescence and hence flotation of fine oil (bitumen) droplets, low operating $\mathrm{pH}$ would seem to be the best. However, low pH is unfavourable for bitumen liberation from sand. More importantly low $\mathrm{pH}$ could cause heterocoagulation ${ }^{14}$ (slime coating) of bitumen with fines that significantly hinders bitumen recovery (to be discussed in the next section). Calcium addition is known to compress the electrical double layer and reduce bitumen-bitumen repulsion, more so at high $\mathrm{pH}$ environment. At high $\mathrm{pH}$ calcium ions may also adsorb specifically onto the bitumen surface, as the surface carboxylic acid groups are deprotonated, reducing bitumen-bitumen adhesion force.

The presence of $\mathrm{Ca}^{2+}$ was found to induce deposition (slime coating) of fines onto bitumen surfaces that would hinder the coalescence of bitumen droplets. Using AFM probe technique Liu et al. ${ }^{34}$ investigated the effect of montmorillonite clay on bitumen-bitumen interactions in aqueous solutions. After a temporary exposure of bitumen surfaces to $0.1 \mathrm{wt} \%$ montmorillonite $(1 \mathrm{mM} \mathrm{KCl}, \mathrm{pH} 8.2)$, the repulsive forces between bitumen surfaces measured in $1 \mathrm{mM} \mathrm{KCl}$ aqueous solution increased substantially, accompanied by a significant reduction in adhesion forces. Such impact was more significant when $\mathrm{Ca}^{2+}$ was present during the exposure of bitumen surfaces to the same montmorillonite suspensions, clearly illustrating the complex nature of water chemistry and fine solids affecting interactions and hence recovery of heavy oil. With recent development of ITFDA, systematic study at different temperatures with varying water chemistry and hydrodynamics of approaching velocities is anticipated to provide further insights on understanding critical role of surface forces in controlling heavy oil coalescence and the nature of governing forces. ${ }^{27}$ 


\subsection{Oil/Water/Fines (Slime Coating)}

Small mineral solids, referred to as "fines" of sizes smaller than $44 \mu \mathrm{m}$ or as clays if they are 2 $\mu \mathrm{m}$ or less, are inevitable in unconventional oil reservoirs. ${ }^{4}$ The presence of clays including kaolinite, illite, montmorillonite, talc, muscovite and others has a significant effect on oil production, ranging from slime coating in recovery to Pickering emulsions in oil-water separation and mature fine tailings in waste management. ${ }^{1}$ Clays consist of two basic layers: a silicon-oxygen tetrahedron sheet $(\mathrm{T})$ and an aluminum-oxygen-hydroxyl octahedron sheet (O). For example, montmorillonite is a three-sheet (TOT) clay mineral, bound by unit layers with $\mathrm{Na}+/ \mathrm{Ca}^{2+}$ ions in the interlayer space. ${ }^{4}$ The challenges presented by clays are largely related to their high specific surface area and anisotropic surface characteristics that dictate the interactions among themselves and with various components of heavy oil deposits. ${ }^{4}$ The AFM has been used only to probe anisotropic surface properties of a limited number of simple platy minerals such as mica, ${ }^{37}$ talc $^{38}$ and kaolinite. ${ }^{39,74}$ Recent study by Yan et al..$^{38}$ for example illustrated the misleading prediction of talc suspension rheology if only average surface (or zeta) potential values are considered, clearly demonstrating the need to determine surface charge characteristics of anisotropic platy clay minerals in guiding correct practical implications. As more such measurements become available, the behaviour of anisotropic mineral solids in unconventional oil reservoirs will become clearer. In this section we focus on interactions of clays with heavy oil (bitumen) encountered in oil recovery process from unconventional oil reservoirs.

Slime coating in mineral processing is regarded as the coverage of a valuable mineral with fines. For example, if an oil droplet is coated in fines, the outer "layer" of the droplet will appear hydrophilic and the oil droplet will have less favourable coalescence with other oil droplets or attachment to air bubbles. For this reason, slime coating is detrimental for oil (bitumen) recovery. Bitumen-bubble attachment in the presence of calcium ions and montmorillonite clays, as will be explained below, is predominately responsible for bitumen slime coating as confirmed with a number of experimental methods, including colloidal probe force, zeta potential distribution, quartz crystal microbalance (QCM) deposition and induction time measurements. ${ }^{1,35,74-76}$ The results from these studies provided scientific insights on observed poor processability of certain types of oil sands formations, base metal deposits and high mineral matter coal.

Long et al. $^{13}$ investigated for example the effect of temperature on interactions between bitumen and fine particles as a function of temperature. Very similar to bitumen/water/sand systems, increasing temperature leads to an increased repulsion and a decrease in adhesion force. Similarly, adhesion of zero is attained at $32^{\circ} \mathrm{C}$, which is the critical minimum temperature to help avoid slime coating of bitumen that could prevent efficient bitumen aeration, explaining the improved processability of weathered ores by processing at elevated temperatures above $32^{\circ} \mathrm{C}^{27}$

To understand the role of fines in "good" and "poor" heavy oil reservoirs (a poor ore has a high amount of divalent cations, fines and hydrophobic solids as seen in section 3), Liu et al. studied interactions between oil (bitumen) and fines or clays determining force profiles using $\mathrm{AFM}^{14}$ and zeta

potential distribution using a zetaphoremeter (SEPHY/CAD). ${ }^{45}$ Here, the colloidal probe was either a 
model clay or fines particle. Due to surface irregularity of a given probe, force measurements were repeated multiple times with different clay/fines-bitumen pairs and plotted together to show the general trend. Rentsch et al. ${ }^{77}$ found the Derjaguin approximation to be valid for heterogeneous colloidal particles. AFM force-distance curves for kaolinite and montmorillonite in $1 \mathrm{mM} \mathrm{KCl}$ aqueous solution at $\mathrm{pH} 8.2$ were similar and slightly repulsive; ${ }^{35}$ most likely due to similar electrokinetics of these clays. $^{45}$ The measured adhesion force in $\mathrm{KCl}$ alone was also similar between kaolinite and montmorillonite. However once $\mathrm{CaCl}_{2}$ was added, adhesion force between montmorillonite and bitumen increased by more than twofold. This study shows the synergistic effect of montmorillonite and calcium (both high adhesion and reduced repulsion) that caused slime coating of bitumen. ${ }^{46}$ To extend the results from model clay systems to the real unconventional oil (bitumen) case, Liu et al. ${ }^{14}$ studied interactions of bitumen with fine solids isolated from two ores of distinctly different processabilities. Figure 4 shows the bitumen-fines interactions determined by AFM probe technique and zeta potential distribution measurements, ${ }^{14}$ and bitumen recovery comparison ${ }^{2}$ between good and poor ores.

Despite great scattering in data points as anticipated for irregular shape particles, Figure 4A shows a clear trend of long range repulsion between bitumen and fines from the good processing ore (filled circle), in contrast to attraction between bitumen and fines from the poor processing (open circle) in corresponding process water. Although both were predominately aluminosilicates, the fines from the poor processing ore contained somewhat hydrophobic particles versus hydrophilic particles from the good processing ore, as determined using film flotation technique. ${ }^{40}$ It is interesting to note a good fit of the force profiles using the classical DLVO theory (solid line) for fines from the good processing ore, with the observed strong repulsion being predominantly due to the electrostatic double-layer interaction. In contrast, the measured force profile for fine solids from the poor processing ore can only be represented with EDLVO (dotted line) due to hydrophobic nature of both fines and bitumen. Figure 4B shows the adhesion force between bitumen and fines in corresponding process water at $\mathrm{pH}$ 7.5-8.0. Clearly, adhesion force between bitumen and fines from the poor processing ore is much stronger with a larger distribution than that between bitumen and fines from the good processing ore. This observation is in direct agreement with the difference in surface wettability between fines from the good and poor processing ores. ${ }^{14}$

Figures 4(C-D) show zeta potential distributions of bitumen and fines individually (subscript 1) and after mixing (subscript 2) in the corresponding process water as in the case of colloidal force measurements. Figure 4-C1 shows zeta potential distribution of bitumen and fines from a good ore, where the bimodal distribution is maintained even after they are mixed, 1:1 ratio (Figure 4-C2), indicating non-coagulative behaviour. In contrast, the zeta distribution of bitumen and poor ore fines (Figure 4-D1) collapses into a single peak when mixed (Figure 4-D2), indicating heterocoagulation of fines and bitumen droplets. A close analysis by Liu et al. showed a much higher calcium ion concentration in the process water from the poor processing ore than that from the good processing ore, indicating a critical role of calcium ions in determining fines coating on hydrophobic bitumen surfaces. The findings in Figure 4 clearly indicate a synergistic effect of the type of fines and divalent (calcium) cations that fines from a poor processing ore with a higher calcium ion content released into the process water have a much stronger affinity to the bitumen surface, attaching to the bitumen 
surface more readily than the fines from the good processing ore. It is slime coating that leads to the observed deterioration of bitumen flotation and ultimately lower bitumen recovery and poorer froth quality, as shown in Figure $4(\mathrm{E}) .^{2}$
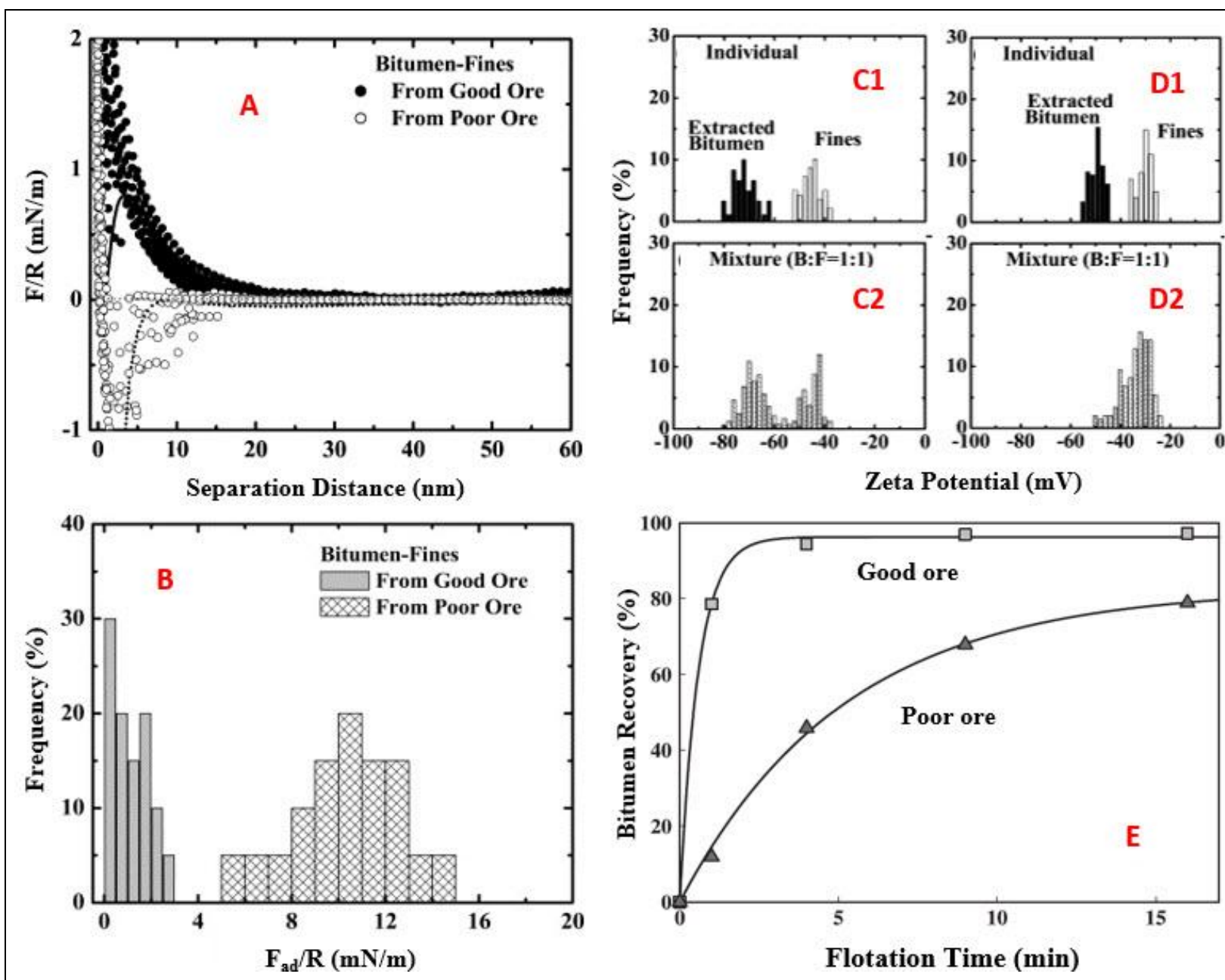

Figure 4: Slime coating of bitumen by fines. A - Normalized interaction force (F/R) between bitumen and fines from good and poor ore overlayed with DLVO fitting curves. [14] B - bitumen-fines normalized adhesion force $\left(F_{a d} / R\right)$ distribution. [14] $\{C-D\}$ - Zeta potential distribution of: $C$ - bitumen and good ore fines, D - bitumen and poor ore fines; secondary numbers denote (1) individual components and (2) mixture. [14] E - Bitumen recovery from good and poor ores. [2]

Using a similar AFM colloidal probe technique, Ren et al. ${ }^{19}$ studied the impact of weathering on interaction and adhesion forces between various fines and bitumen-covered silicon wafer in water at $\mathrm{pH}$ 8-8.6 with $1 \mathrm{mM} \mathrm{KCl}$. The probes in their study were made from fines extracted from (1) good, (2) artificially weathered and (3) naturally weathered ores, in comparison with the case of probe 2 being exposed to UV light for 12 hours (4). They observed a repulsive barrier prior to jump-in of probe 1 to bitumen with weak adhesion, as anticipated for fines from good processing ores. In contrast there exists a much smaller repulsive barrier and stronger adhesion force between bitumen and fines from the 
weathered ores either artificially (probe 2 ) or naturally (probe 3). These fines could readily slime-coat on a bitumen droplet, leading to poor processability. Interestingly, UV treatment of probe 2 restored a strong repulsive force with no adhesion force between the probe and bitumen in the same aqueous solutions, indicating the reverse in fines wettability back to their hydrophilic state before UV treatment as anticipated. While UV treatment is proven successful in restoring hydrophilic nature of fine solids, it may also degrade heavy oil (bitumen), causing unforeseen negative impact of UV treatment on oil chemistry and hence processability of ores. Furthermore, the commercial adoption of UV treatment to improve the processability of weathered reservoirs or oil sands ores remains challenging. Ding et al. ${ }^{41}$ proposed an alternative method to alter colloidal interactions between fine solids and bitumen by conditioning a poor processing ore using the bacterium $B$. subtilis, which is capable of degrading polyaromatic hydrocarbons such as asphaltenes and resins in the bacterial culture solution for an extended period of time (e.g., 33 days). Under the identical aqueous solution conditions $(1 \mathrm{mM} \mathrm{KCl}$ at $\mathrm{pH}$ 8.0-8.5), a long-range attractive force and strong adhesion force were measured between fines from untreated ores and bitumen, in contrast to a negligible attractive force and a significantly reduced adhesion force for particles isolated after bacteria treatment of the same ore. It is clear that microbial treatment could change solids' wettability and shows great potential in improving the processability of poor processing ores.

\section{Surface Forces in Oil-Water Separation from Emulsions}

As mentioned in the introduction, the final step in unconventional oil production before upgrading and/or refining is to separate the recovered oil from water and solids in the form of both $\mathrm{W} / \mathrm{O}$ or $\mathrm{O} / \mathrm{W}$ emulsions, depending on the production methods used. In reality, the natural components of reservoir such as asphaltenes and fines can either individually or in combination stabilize both types of emulsions and rag layer formation that are detrimental to oil-water separation. It is therefore of great importance to understand colloidal forces between oil droplets and solids in water or between water droplets in oil in addition to colloidal forces between two droplets in an immiscible liquid in the presence of various natural components of heavy oil reservoirs. For this review, we will focus specifically on the Oil/Water/Oil and Water/Oil/Water interactions in the presence of asphaltenes. In both cases, asphaltenes could be present at the interface, residing mainly in the organic phase. Destabilization of an emulsion involves droplet flocculation driven by attractive surface forces with high adhesion and coalesce, if interfacial films are unstable, resulting in a phase separation.

\subsection{Oil/Water/Oil}

Using AFM colloidal probe technique, Liu et al. ${ }^{47}$ determined colloidal forces between asphaltene surfaces immobilized on solid surfaces in aqueous solutions. To form stable anchor of asphaltenes on solid surfaces used in the colloidal force measurements, silica colloidal probe and silicon wafer were both hydrophobized prior to being coated with asphaltene films using the LangmuirBlodgett method. In their study ${ }^{47}$ addition of electrolyte ( $\mathrm{KCl}$ or calcium ion) was found to significantly decrease long range repulsive forces with a marginal decrease in adhesion force as anticipated from electrical double-layer compression. Decreasing temperature and $\mathrm{pH}$ led to a reduction in repulsive 
force barrier and an increase in adhesion forces. Extended DLVO theory was used to describe the measured force profiles with the hydrophobic and electrostatic contributions dominant beyond 4-6 $\mathrm{nm}$ and short-range repulsion dominant at less than 4-6 $\mathrm{nm}$. The short range repulsion was attributed to the steric overlap of aggregated aromatic cores. Thanks to pioneer work on the droplet probe AFM technique by Dagastine et al., ${ }^{49}$ Shi et al. recently measured directly interaction forces of oil (toluene with dissolved asphaltenes) drops in water by anchoring one oil droplet to a hydrophobized gold patch on the apex of a tipless AFM cantilever and the other to a hydrophobized glass slide. ${ }^{48} \mathrm{~A}$ theoretical model based on the augmented Young-Laplace equation and Reynolds lubrication theory was used to calculate droplet profiles (film thickness as a function of radius). ${ }^{32,48}$ The overall observations from their study corroborated very well with the findings by Liu et al., ${ }^{47}$ though Shi et al. ${ }^{48}$ observed drop coalescence with the addition of calcium, most likely due to a higher background electrolyte concentration and lower solution $\mathrm{pH}$.

Due to unknown molecular structures of asphaltenes that greatly hindered the progress on understanding the role of molecular forces in emulsion stabilization, surface forces were measured using asphaltene "model" compounds for a more nuanced understanding of surface forces at play. Using SFA recently for example, Wang et al. ${ }^{50}$ studied interaction forces for an asphaltene model compound known as C5Pe in aqueous solutions. C5Pe, also known as $\mathrm{N}$-(1-hexylheptyl)-N'-(5-carboxylicpentyl) perylene-3,4,9,10-tetracarboxylic bisimide, consists of four aromatic rings fused together with three cyclic rings containing heteroatoms of $\mathrm{O}$ and $\mathrm{N} .{ }^{50}$ The interaction force (F/R) between C5Pe-coated surfaces was found to be repulsive, that is of steric and electrostatic origin. Alexander de Gennes theory for polymer brushes (AdG) appears to fit force-distance profiles well at short separation distance and high compression, while only electrostatic interaction (ionized carboxylic group) was present at large separation and low compression. The adhesion was found to decrease with increasing electrolyte concentration and $\mathrm{pH}$, attributed to a decrease in hydrophobic attraction.

\subsection{Water/Oil/Water}

Wang et al. ${ }^{51}$ were among the first to determine directly interaction forces between asphaltene surfaces in organic solvents, ranging from toluene (good asphaltene solvent) to $\mathrm{n}$-haptane (poor asphaltene solvent) or in heptol (a $n$-heptane : toluene mixture) using AFM. Asphaltene interfacial films transferred from water-toluene interfaces onto both a silica colloidal probe and flat silica wafer using Langmuir-Blodgett method were used in this study. Figure $5 A^{51}$ shows the measured interaction forces $(F / R)$ while the circular inset shows an average asphaltene structure as predicted by Yen-Mullins model. $^{78}$ The interaction forces are increasingly repulsive with increasing toluene content (red curve) due to steric non-DLVO forces resulting from the swelling of asphaltene layers in a good solvent such as toluene. For pure $n$-heptane (blue curve) and up to 0.2 toluene volume fraction, the steric repulsion is replaced by a weak van der Waals attractive force, believed to be responsible for asphaltene precipitation with $\pi-\pi$ stacking. ${ }^{1,51}$ Natarjan et al. observed similar findings from SFA measurements between asphaltenes deposited on mica: deposited asphaltene films are much more compressed in heptane than in toluene with a hard wall thickness of $20 / 2$ and $40 / 2 \mathrm{~nm}$, respectively. ${ }^{53}$ These findings have practical implications in explaining, for example, the use of paraffinic solvent in precipitation of 
asphaltenes to enhance oil-water/solids separation in froth treatment of oil sands extraction. ${ }^{7}$ SFA study also showed a strong time-dependent buildup of asphaltenes on mica surfaces from $1 \mathrm{wt} \%$ asphaltenein-toluene solution, with the adsorbed layer thickness increasing from 30/2 nm at $5 \mathrm{~min}$ to 100/2 nm at $1.5 \mathrm{~h}$ and $300 / 2 \mathrm{~nm}$ after $4 \mathrm{~h}$ adsorption. ${ }^{54}$
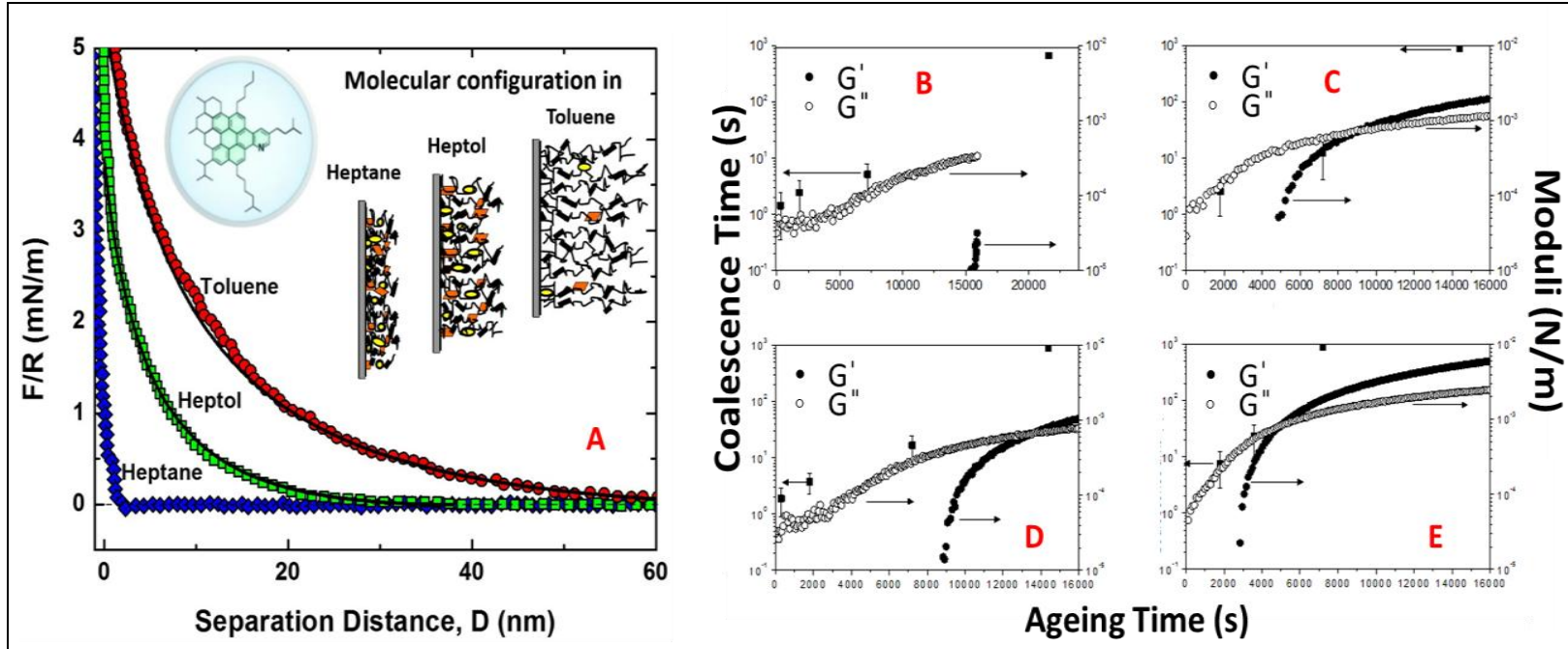

Ageing Time (s)

Figure 5: Asphaltene-asphaltene interaction: A: Normalized interaction force $(F / R)$ as a function of distance of asphaltene-covered colloidal probe and asphaltene deposited film in toluene (red), heptol (green) and heptane (blue) [51]; circular inset: sample asphaltene molecular structure. [78] $\{B-E\}$ Comparison of water drop coalescence time and viscoelastic $\left(G^{\prime}=\right.$ storage modulus, $G^{\prime \prime}=$ loss modulus) properties of asphaltene interfacial films: $B-0.1 \mathrm{~g} / \mathrm{L}$ asphaltene in toluene, $\mathrm{C}-0.1 \mathrm{~g} / \mathrm{L}$ asphaltene in heptol 1:1, D-0.4 g/L asphaltene in toluene, $\mathrm{E}-0.4 \mathrm{~g} / \mathrm{L}$ asphaltene in heptol 1:1. [57]

To link the measured dynamics of asphaltene adsorption and interaction forces with emulsion stability and physicochemical properties of interfacial films, Harbottle et al. correlated in Figure 5(B-E) the water drop coalescence time measured using ITFDA with viscoelastic behaviour of asphaltene interfacial films formed under the identical conditions of asphaltene-in-toluene solution in contact with water. ${ }^{57}$ At short ageing time all the films are viscous dominant $\left(G^{\prime \prime}>G^{\prime}\right)$ with the corresponding droplets coalescing within the order of seconds. However, the films become increasingly elastic-dominant $\left(G^{\prime}>G^{\prime \prime}\right)$ at longer ageing time, leading to stable droplets without coalescence and hence stable W/O emulsions. Using TLF balance technique Tchoukov et al. observed similar effects of ageing that led to much thicker interfacial films accompanied with the formation of heterogeneous sub-micrometer aggregates. ${ }^{58}$ From disjoining pressure isotherms of various model W/O emulsions, Taylor et al. ${ }^{59}$ observed a high positive disjoining pressure $\Pi$ and hence stable films for systems with high asphaltene concentrations. Although the simplified Stefan-Reynolds model (by assuming $\Pi=0$ ) seems to predict the measured film thicknesses reasonably well for the results from both groups, $\left({ }^{58}{ }^{59}\right)$ applying StokesReynolds-Young-Laplace model to further experimental data at lower asphaltene concentrations with and without maltenes would help in elucidating the nature of the disjoining pressure. Recent studies also suggest that only a small fraction of asphaltenes are responsible for emulsion stabilization. ${ }^{79}$ Thus future experiments measuring interaction forces for this particular fraction of asphaltenes using droplet 
probe AFM technique, TLF balance and ITFDA will provide further insights on molecular mechanisms of emulsion stabilization by asphaltenes. The measurements could be extended to include fine solids and clays of variable surface wettability to make the measurements of more practical implications.

Finally it is interesting to note similarities in adsorption kinetics of asphaltene model compound C5Pe to asphaltenes from toluene and $n$-heptane. ${ }^{55}$ In contrast to asphaltenes, C5Pe showed a negligible swelling in toluene, which is not unexpected as asphaltenes represent a class of molecules with variable structures in contrast to single molecular species of C5Pe. It may be valuable to use a mixture of several model asphaltene compounds in future studies to better mimic interactions of real asphaltene systems. It should be noted that with limited space and citations, this review by no means is a complete compilation of the work on the role of colloidal forces in the field of unconventional oil processing. One example is the critical role of clay interactions in fluid fine or mature fine tailings management which is a grand scale challenge to mineable oil sands industry in Canada. To provide a better control of formation of Pickering emulsions, rag layers and mature fine tailings in unconventional oil processing, much needs to be done to study anisotropic surface properties of clays and understand molecular interactions of various clay surfaces with natural components of heavy oil. We also omitted the colloidal forces in chemical demulsification. A good overview on chemical demulsification can be found elsewhere. ${ }^{1}$

\section{Concluding Remarks}

The role of colloidal forces in two main steps of unconventional oil processing - oil liberation from host rocks and separating oil from water-oil and oil-water emulsions - is critically reviewed. The review was organized into specific interactions such as oil-sand, oil-bubble, bubble-sand, oil-fines, oil-oil (in water) and water-water (in oil). The surface forces and adhesion forces for each specific system were reviewed as a function of input variables such as $\mathrm{pH}$, mono and divalent ions, surfactants, temperature, etc. When many interactions have competing requirements, a thorough understanding of surface forces governing each one of these essential systems allows one to tailor a given process for maximum oil recovery. Although significant advances have been made over the years of research, future research opportunities remain. In particular, opportunities exist to investigate the effect of hydrodynamics and temperature on colloidal interactions by using more sophisticated models for experimental data interpretation to shed light on the nature of interaction forces and corresponding practical implications.

\section{Acknowledgements}

The financial support for completing this review from NSERC (Natural Sciences and Engineering Research Council of Canada) Industrial Research Chair in Oil Sands Engineering and from the National Science Foundation of China (Grant number 51274129) is gratefully acknowledged. 


\section{References}

${ }^{*}$ - of special interest, ${ }^{* *}$ - of outstanding interest

$\left(1^{* *}\right)$ He, L.; Lin, F.; Li, X.; Sui, H.; Xu, Z. Interfacial Sciences in Unconventional Petroleum Production: From Fundamentals to Applications. Chem. Soc. Rev. 2015, 44, 5446-5494.

(2) Long, J.; Xu, Z.; Masliyah, J. H. In Bitumen Recovery of Oil from Oil Sand; Encyclopedia of Surface and Colloid Science; Taylor \& Francis: 2009; pp 1-18.

(3) International Energy Agency In Resources to Reserves 2013: Oil, Gas and Coal Technologies for the Energy Markets of the Future; IEA Publications: France, 2013; pp 1-272.

(4) Masliyah, J. H.; Czarnecki, J.; Xu, Z. In Chapter 4: Physical and Chemical Properties of Oil Sands; Handbook on Theory and Practice of Bitumen Recovery from Athabasca Oil Sands; Kingsley Knowledge Publishing: Canada, 2011; Vol. 1: Theoretical Basis, pp 173-265.

(5) International Energy Agency In World Energy Outlook 2012; IEA Publications: France, 2012; pp 668.

(6) Shah, A.; Fishwick, R.; Wood, J.; Leeke, G.; Rigby, S.; Greaves, M. A Review of Novel Techniques for Heavy Oil and Bitumen Extraction and Upgrading. Energy Environ. Sci. 2010, 3, 700-714.

$\left(7^{* *}\right)$ Masliyah, J.; Zhou, Z. J.; Xu, Z. H.; Czarnecki, J.; Hamza, H. Understanding Water-Based Bitumen Extraction from Athabasca Oil Sands. Can. J. Chem. Eng. 2004, 82, 628-654.

(8) Thomas, S. Enhanced Oil Recovery - an Overview. Oil Gas Sci. Technol. 2008, 63, 9-19.

(9) Martinez-Palou, R.; Mosqueira, M. d. L.; Zapata-Rendon, B.; Mar-Juarez, E.; Bernal-Huicochea, C.; Clavel-Lopez, J. d. I. C.; Aburto, J. Transportation of Heavy and Extra-Heavy Crude Oil by Pipeline: A Review. J. Pet. Sci. Eng. 2011, 75, 274-282.

(10*) Harbottle, D.; Liang, C.; El-Thaher, N.; Liu, Q.; Masliyah, J.; Xu, Z. In Chapter 11: Particle-Stabilized Emulsions in Heavy Oil Processing; Ngai, T., Bon, S., Eds.; Particle-Stabilized Emulsions and Colloids : Formation and Applications; The Royal Society of Chemistry: 2015; pp 283-316.

(11*) Wang, L. X.; Sharp, D.; Masliyah, J.; Xu, Z. H. Measurement of Interactions between Solid Particles, Liquid Droplets, and/Or Gas Bubbles in a Liquid using an Integrated Thin Film Drainage Apparatus. Langmuir 2013, 29, 3594-3603.

(12) Parker, J. L. A Novel Method for Measuring the Force between 2 Surfaces in a Surface Force Apparatus. Langmuir 1992, 8, 551-556.

$\left(13^{*}\right)$ Long, J.; Drelich, J.; Xu, Z.; Masliyah, J. H. Effect of Operating Temperature on Water-Based Oil Sands Processing. Can. J. Chem. Eng. 2007, 85, 726-738.

$\left(14^{* *}\right)$ Liu, J. J.; Xu, Z. H.; Masilyah, J. Interaction Forces in Bitumen Extraction from Oil Sands. J. Colloid Interface Sci. 2005, 287, 507-520. 
(15) Zhao, H.; Long, J.; Masliyah, J. H.; Xu, Z. Effect of Divalent Cations and Surfactants on Silica-Bitumen Interactions. Ind. Eng. Chem. Res. 2006, 45, 7482-7490.

(16) Zhang, Y.; Ding, M.; Liua, J.; Jia, W.; Ren, S. Studies on Bitumen-Silica Interaction in Surfactants and Divalent Cations Solutions by Atomic Force Microscopy. Colloid Surf. A-Physicochem. Eng. Asp. 2015, 482, 241-247.

$\left(17^{*}\right)$ Liu, J. J.; Xu, Z. H.; Masliyah, J. Processability of Oil Sand Ores in Alberta. Energy Fuels 2005, 19, 2056-2063.

(18) Zhao, H.; Dang-Vu, T.; Long, J.; Xu, Z.; Masliyah, J. H. Role of Bicarbonate lons in Oil Sands Extraction Systems with a Poor Processing Ore. J. Dispersion Sci. Technol. 2009, 30, 809-822.

(19) Ren, S.; Zhao, H.; Long, J.; Xu, Z.; Masliyah, J. Understanding Weathering of Oil Sands Ores by Atomic Force Microscopy. AIChE J. 2009, 55, 3277-3285.

(20*) Hogshead, C. G.; Manias, E.; Williams, P.; Lupinsky, A.; Painter, P. Studies of Bitumen-Silica and OilSilica Interactions in Ionic Liquids. Energy Fuels 2011, 25, 293-299.

(21) Liu, J. J.; Xu, Z. H.; Masliyah, J. Studies on Bitumen-Silica Interaction in Aqueous Solutions by Atomic Force Microscopy. Langmuir 2003, 19, 3911-3920.

(22*) Long, J.; Zhang, L.; Xu, Z.; Masliyah, J. H. Colloidal Interactions between Langmuir-Blodgett Bitumen Films and Fine Solid Particles. Langmuir 2006, 22, 8831-8839.

(23) Li, H.; Long, J.; Xu, Z.; Masliyah, J. H. Synergetic Role of Polymer Flocculant in Low-Temperature Bitumen Extraction and Tailings Treatment. Energy Fuels 2005, 19, 936-943.

(24) Long, J.; Xu, Z.; Masliyah, J. On the Role of Temperature in Oil Sands Processing. Energy Fuels 2005, $19,1440-1446$.

(25*) Englert, A. H.; Ren, S.; Masliyah, J. H.; Xu, Z. Interaction Forces between a Deformable Air Bubble and a Spherical Particle of Tuneable Hydrophobicity and Surface Charge in Aqueous Solutions. J. Colloid Interface Sci. 2012, 379, 121-129.

(26) Ren, S.; Masliyah, J.; Xu, Z. Studying Bitumen-Bubble Interactions using Atomic Force Microscopy. Colloid Surf. A-Physicochem. Eng. Asp. 2014, 444, 165-172.

(27) Wang, L.; Xu, Z.; Masliyah, J. H. Dissipation of Film Drainage Resistance by Hydrophobic Surfaces in Aqueous Solutions. J. Phys. Chem. C 2013, 117, 8799-8805.

(28) Shi, C.; Cui, X.; Xie, L.; Liu, Q.; Chan, D. Y. C.; Israelachvili, J. N.; Zeng, H. Measuring Forces and Spatiotemporal Evolution of Thin Water Films between an Air Bubble and Solid Surfaces of Different Hydrophobicity. ACS Nano 2015, 9, 95-104.

$\left(29^{* *}\right)$ Ducker, W. A.; Xu, Z. H.; Israelachvili, J. N. Measurements of Hydrophobic and DLVO Forces in Bubble-Surface Interactions in Aqueous-Solutions. Langmuir 1994, 10, 3279-3289. 
(30) Tabor, R. F.; Manica, R.; Chan, D. Y. C.; Grieser, F.; Dagastine, R. R. Repulsive Van Der Waals Forces in Soft Matter: Why Bubbles Do Not Stick to Walls. Phys. Rev. Lett. 2011, 106, 064501.

(31) Preuss, M.; Butt, H. Direct Measurement of Particle-Bubble Interactions in Aqueous Electrolyte: Dependence on Surfactant. Langmuir 1998, 14, 3164-3174.

$\left(32^{* *}\right)$ Chan, D. Y. C.; Klaseboer, E.; Manica, R. Film Drainage and Coalescence between Deformable Drops and Bubbles. Soft Matter 2011, 7, 2235-2264.

(33) Shahalami, M.; Wang, L.; Wu, C.; Masliyah, J. H.; Xu, Z.; Chan, D. Y. C. Measurement and Modeling on Hydrodynamic Forces and Deformation of an Air Bubble Approaching a Solid Sphere in Liquids. Adv. Colloid Interface Sci. 2015, 217, 31-42.

(34) Liu, J. J.; Xu, Z. H.; Masliyah, J. Colloidal Forces between Bitumen Surfaces in Aqueous Solutions Measured with Atomic Force Microscope. Colloid Surf. A-Physicochem. Eng. Asp. 2005, 260, 217228.

(35) Liu, J. J.; Xu, Z. H.; Masliyah, J. Role of Fine Clays in Bitumen Extraction from Oil Sands. AIChE J. 2004, 50, 1917-1927.

(36) Li, H.; Long, J.; Xu, Z.; Masliyah, J. H. Novel Polymer Aids for Low-Grade Oil Sand Ore Processing. Can. J. Chem. Eng. 2008, 86, 168-176.

(37) Zhao, H.; Bhattacharjee, S.; Chow, R.; Wallace, D.; Masliyah, J. H.; Xu, Z. Probing Surface Charge Potentials of Clay Basal Planes and Edges by Direct Force Measurements. Langmuir 2008, 24, 12899-12910.

(38) Yan, L.; Masliyah, J. H.; Xu, Z. Understanding Suspension Rheology of Anisotropically-Charged Platy Minerals from Direct Interaction Force Measurement using AFM. Curr. Opin. Colloid Interface Sci. 2013, 18, 149-156.

(39*) Liu, J.; Sandaklie-Nikolova, L.; Wang, X.; Miller, J. D. Surface Force Measurements at Kaolinite Edge Surfaces using Atomic Force Microscopy. J. Colloid Interface Sci. 2014, 420, 35-40.

(40) Liu, J. J.; Xu, Z. H.; Masliyah, J. Interaction between Bitumen and Fines in Oil Sands Extraction System: Implication to Bitumen Recovery. Can. J. Chem. Eng. 2004, 82, 655-666.

(41) Ding, M. -S.; Jia, W. -H.; Lv, Z. -F.; Ren, S. -L. Improving Bitumen Recovery from Poor Processing Oil Sands using Microbial Pretreatment. Energy Fuels 2014, 28, 7712-7720.

(42) Long, J.; Xu, Z.; Mashyah, J. Role of Illite-Illite Interactions in Oil Sands Processing. Colloid Surf. APhysicochem. Eng. Asp. 2006, 281, 202-214.

(43) Li, H.; Long, J.; Xu, Z.; Masliyah, J. H. Effect of Molecular Weight and Charge Density on the Performance of Polyacrylamide in Low-Grade Oil Sand Ore Processing. Can. J. Chem. Eng. 2008, 86, 177-185. 
44) Long, J.; Li, H.; Xu, Z.; Masliyah, J. H. Improving Oil Sands Processability using a TemperatureSensitive Polymer. Energy Fuels 2011, 25, 701-707.

(45) Liu, J.; Zhou, Z.; Xu, Z.; Masliyah, J. Bitumen-Clay Interactions in Aqueous Media Studied by Zeta Potential Distribution Measurement. J. Colloid Interface Sci. 2002, 252, 409-418.

(46) Kasongo, T.; Zhou, Z.; Xu, Z. H.; Masliyah, J. Effect of Clays and Calcium lons on Bitumen Extraction from Athabasca Oil Sands using Flotation. Can. J. Chem. Eng. 2000, 78, 674-681.

(47) Liu, J.; Zhang, L.; Xu, Z.; Masliyah, J. Colloidal Interactions between Asphaltene Surfaces in Aqueous Solutions. Langmuir 2006, 22, 1485-1492.

(48*) Shi, C.; Zhang, L.; Xie, L.; Lu, X.; Liu, Q.; Mantilla, C. A.; van den Berg, F. G. A.; Zeng, H. Interaction Mechanism of Oil-in-Water Emulsions with Asphaltenes Determined using Droplet Probe AFM. Langmuir 2016, 32, 2302-2310.

(49**) Dagastine, R. R.; Manica, R.; Carnie, S. L.; Chan, D. Y. C.; Stevens, G. W.; Grieser, F. Dynamic Forces between Two Deformable Oil Droplets in Water. Science 2006, 313, 210-213.

(50) Wang, J.; Lu, Q.; Harbottle, D.; Sjoblom, J.; Xu, Z.; Zeng, H. Molecular Interactions of a Polyaromatic Surfactant C5Pe in Aqueous Solutions Studied by a Surface Forces Apparatus. J. Phys. Chem. B 2012, 116, 11187-11196.

(51) Wang, S.; Liu, J.; Zhang, L.; Masliyah, J.; Xu, Z. Interaction Forces between Asphaltene Surfaces in Organic Solvents. Langmuir 2010, 26, 183-190.

(52*) Wang, S.; Liu, J.; Zhang, L.; Xu, Z.; Masliyah, J. Colloidal Interactions between Asphaltene Surfaces in Toluene. Energy Fuels 2009, 23, 862-869.

(53*) Natarajan, A.; Xie, J.; Wang, S.; Liu, Q.; Masliyah, J.; Zeng, H.; Xu, Z. Understanding Molecular Interactions of Asphaltenes in Organic Solvents using a Surface Force Apparatus. J. Phys. Chem. C 2011, 115, 16043-16051.

(54) Natarajan, A.; Kuznicki, N.; Harbottle, D.; Masliyah, J.; Zeng, H.; Xu, Z. Understanding Mechanisms of Asphaltene Adsorption from Organic Solvent on Mica. Langmuir 2014, 30, 9370-9377.

(55) Wang, J.; Opedal, N. v. d. T.; Lu, Q.; Xu, Z.; Zeng, H.; Sjoblom, J. Probing Molecular Interactions of an Asphaltene Model Compound in Organic Solvents using a Surface Forces Apparatus (SFA). Energy Fuels 2012, 26, 2591-2599.

(56) Drummond, C.; Israelachvili, J. Fundamental Studies of Crude Oil-Surface Water Interactions and its Relationship to Reservoir Wettability. J Pet Sci Eng 2004, 45, 61-81.

$\left(57^{*}\right)$ Harbottle, D.; Chen, Q.; Moorthy, K.; Wang, L.; Xu, S.; Liu, Q.; Sjoblom, J.; Xu, Z. Problematic Stabilizing Films in Petroleum Emulsions: Shear Rheological Response of Viscoelastic Asphaltene Films and the Effect on Drop Coalescence. Langmuir 2014, 30, 6730-6738. 
(58*) Tchoukov, P.; Yang, F.; Xu, Z.; Dabros, T.; Czarnecki, J.; Sjoblom, J. Role of Asphaltenes in Stabilizing Thin Liquid Emulsion Films. Langmuir 2014, 30, 3024-3033.

(59) Taylor, S. D.; Czarnecki, J.; Masliyah, J. Disjoining Pressure Isotherms of Water-in-Bitumen Emulsion Films. J. Colloid Interface Sci. 2002, 252, 149-160.

(60) Czarnecki, J.; Tchoukov, P.; Dabros, T. Possible Role of Asphaltenes in the Stabilization of Water-inCrude Oil Emulsions. Energy Fuels 2012, 26, 5782-5786.

(61) Khristov, K.; Taylor, S.; Czarnecki, J.; Masliyah, J. Thin Liquid Film Technique - Application to WaterOil-Water Bitumen Emulsion Films. Colloid Surf. A-Physicochem. Eng. Asp. 2000, 174, 183-196.

(62) Tchoukov, P.; Czarnecki, J.; Dabros, T. Study of Water-in-Oil Thin Liquid Films: Implications for the Stability of Petroleum Emulsions. Colloid Surf. A-Physicochem. Eng. Asp. 2010, 372, 15-21.

(63) Yang, F.; Tchoukov, P.; Pensini, E.; Dabros, T.; Czarnecki, J.; Masliyah, J.; Xu, Z. Asphaltene Subfractions Responsible for Stabilizing Water-in-Crude Oil Emulsions. Part 1: Interfacial Behaviors. Energy Fuels 2014, 28, 6897-6904.

(64) Czarnecki, J.; Tchoukov, P.; Dabros, T.; Xu, Z. Role of Asphaltenes in Stabilisation of Water in Crude Oil Emulsions. Can. J. Chem. Eng. 2013, 91, 1365-1371.

(65) Matthews, J. G.; Shaw, W. H.; MacKinnon, M. D.; Cuddy, R. G. Development of Composite Tailings Technology at Syncrude Canada. Int. J. Min. Reclam. Env. 2002, 16, 24-39.

(66) Liu, J. J.; Zhou, Z.; Xu, Z. H. Electrokinetic Study of Hexane Droplets in Surfactant Solutions and Process Water of Bitumen Extraction Systems. Ind. Eng. Chem. Res. 2002, 41, 52-57.

(67) Ren, S.; Dang-Vu, T.; Zhao, H.; Long, J.; Xu, Z.; Masliyah, J. Effect of Weathering on Surface Characteristics of Solids and Bitumen from Oil Sands. Energy Fuels 2009, 23, 334-341.

(68) Israelachvili, J. In Intermolecular and Surface Forces, third edition; Academic Press: San Diego, 2011.

(69) Wang, L.; Dang-Vu, T.; Xu, Z.; Masliyah, J. H. Use of Short-Chain Amine in Processing of Weathered/Oxidized Oil Sands Ores. Energy Fuels 2010, 24, 3581-3588.

(70) Dagastine, R.; White, L. Forces between a Rigid Probe Particle and a Liquid Interface - II. the General Case. J. Colloid Interface Sci. 2002, 247, 310-320.

(71*) Butt, H. A. Technique for Measuring the Force between a Colloidal Particle in Water and a Bubble. J. Colloid Interface Sci. 1994, 166, 109-117.

(72) Schaeffel, D.; Koynov, K.; Vollmer, D.; Butt, H.; Schoenecker, C. Local Flow Field and Slip Length of Superhydrophobic Surfaces. Phys. Rev. Lett. 2016, 116, 134501. 
(73) Alagha, L.; Wang, S.; Yan, L.; Xu, Z.; Masliyah, J. Probing Adsorption of Polyacrylamide-Based Polymers on Anisotropic Basal Planes of Kaolinite using Quartz Crystal Microbalance. Langmuir 2013, 29, 3989-3998.

(74) Gu, G. X.; Xu, Z. H.; Nandakumar, K.; Masliyah, J. Effects of Physical Environment on Induction Time of Air-Bitumen Attachment. Int. J. Miner. Process. 2003, 69, 235-250.

(75*) Chen, Q.; Xu, S.; Liu, Q.; Masliyah, J.; Xu, Z. QCM-D Study of Nanoparticle Interactions. Adv. Colloid Interface Sci. 2016, 233, 94-114.

(76) Rentsch, S.; Pericet-Camara, R.; Papastavrou, G.; Borkovec, M. Probing the Validity of the Derjaguin Approximation for Heterogeneous Colloidal Particles. Phys. Chem. Chem. Phys. 2006, 8, 2531-2538.

$\left(77^{* *}\right)$ Mullins, O. C., et al Advances in Asphaltene Science and the Yen-Mullins Model. Energy Fuels 2012, 26, 3986-4003.

$\left(78^{* *}\right)$ Kilpatrick, P. K. Water-in-Crude Oil Emulsion Stabilization: Review and Unanswered Questions. Energy Fuels 2012, 26, 4017-4026. 


\section{Oil/Water/Bubble}
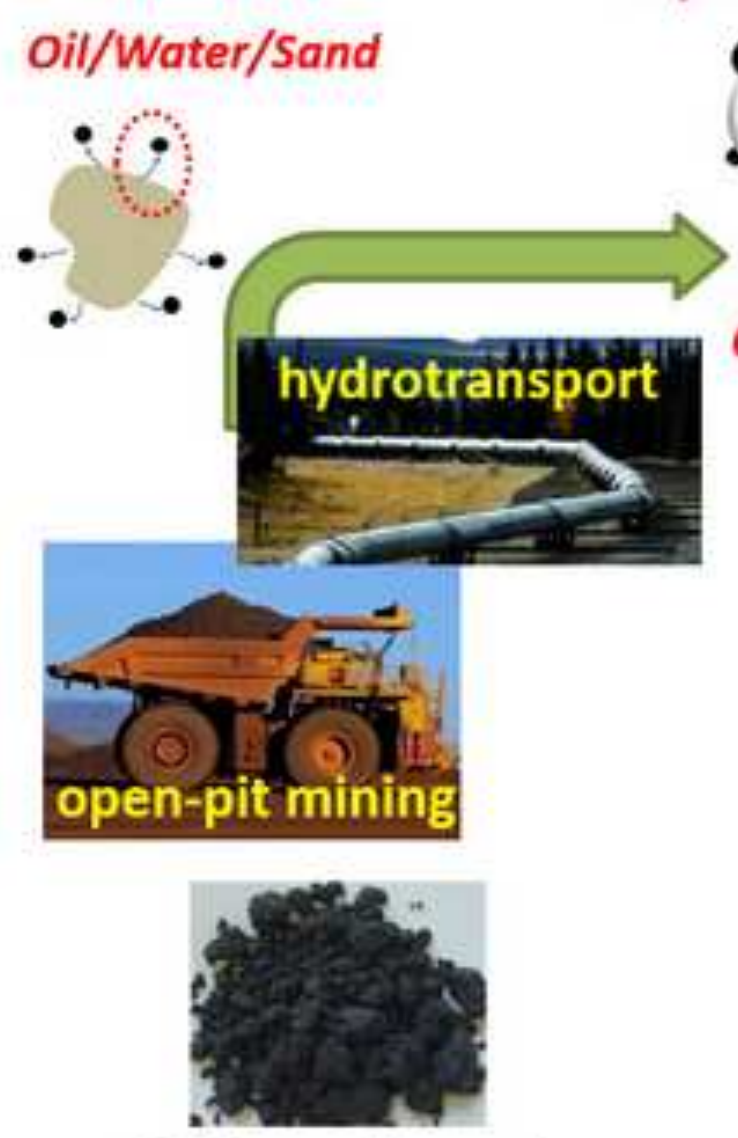

1.8 tons oil sands

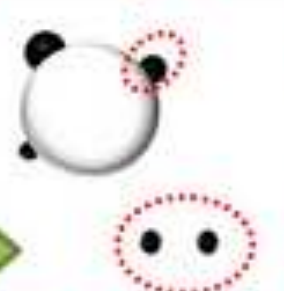

Oil/Water/Oil
Oil/Water/Clay<smiles>C1CCC2CCCC2C1</smiles>
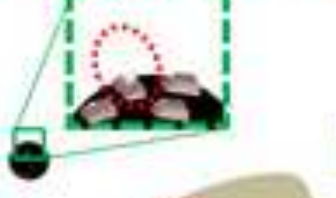

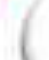
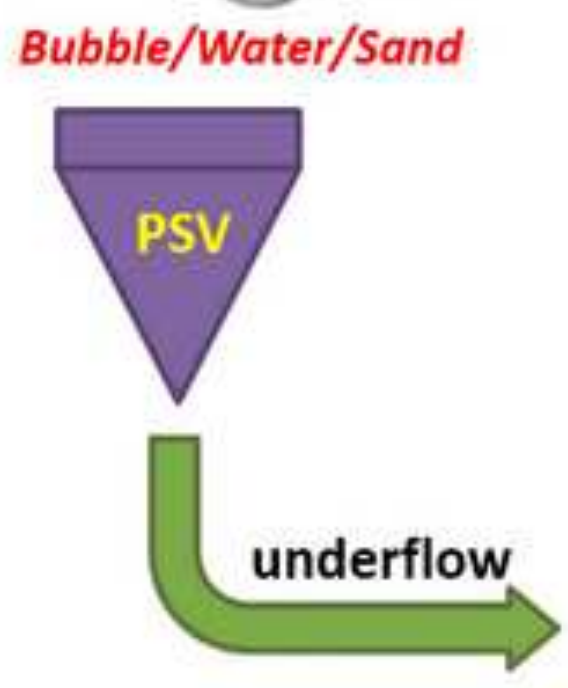

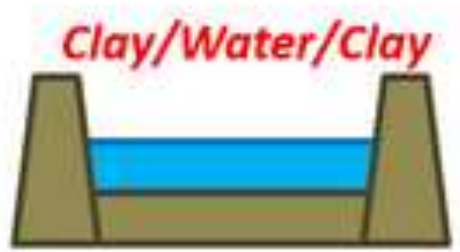

$3.3 \mathrm{~m}^{3}$ tailings

Froth Treatment

Oil/Water/Oil

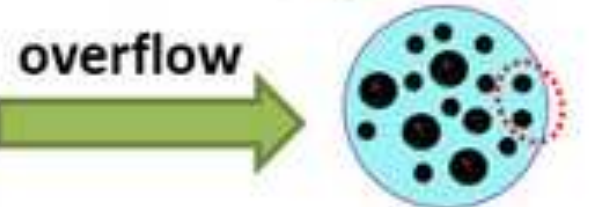

emulsions

Asphaltenes

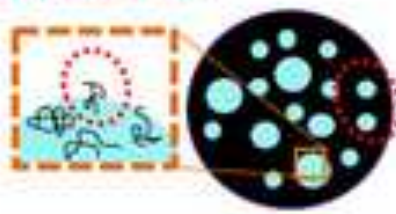

Water/Oil/Water

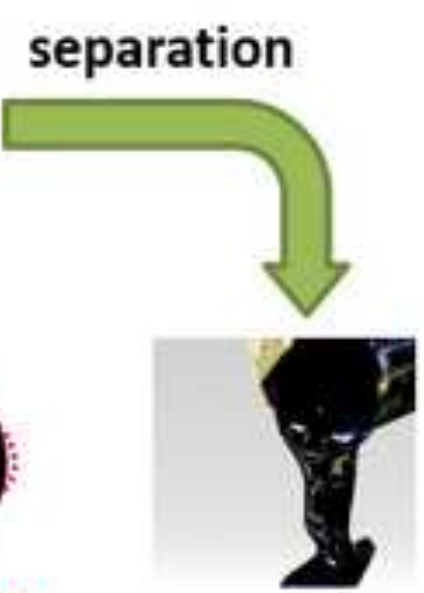

1 bbl bitumen

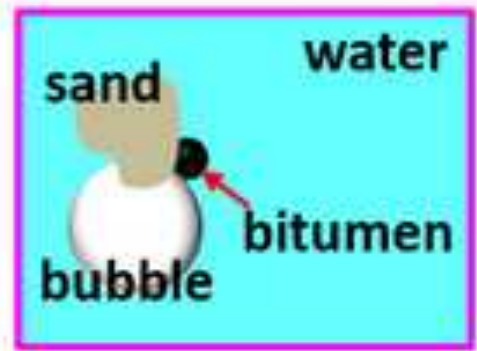

